\title{
Social Technology (TS) and Artificial Intelligence (AI)... Brief Reflections and Perspectives
}

\author{
Bomfim FR $^{1 *}$ and Gimenez Pereira $\mathrm{MC}^{2}$ \\ ${ }^{1}$ Postdoctoral student of the postgraduate program in Law at the federal university of Bahia/ \\ Brasil \\ ${ }^{2}$ Posdoctoral advisor of the posgraduate program in Law at the federal university of Bahia, \\ Brasil
}

*Corresponding author: Felipe Rodrigues Bomfim, Postdoctoral student of the postgraduate program in Law at the federal university of Bahia/Brasil. PPGD/UFBA, Email: bomfimster@gmail.com

\section{Abstract}

The purpose of this article is to reflect the possible connections between Social Technology (TS) and Artificial Intelligence (AI), in an attempt to understand some limits and possibilities in the contemporary world. Is it possible to envision any articulation between ST and AI in the health area? What would be the gains and social impacts of this possible articulation? It is these concerns that we intend to reflect on. The article is divided into two moments. In the first moment, we contextualized Social Technology (TS) and Artificial Intelligence (AI). In the second and last moment we present the Artificial Partner Technology (TSA), its meaning and perspectives.

Keywords: Social Technology; Artificial Intelligence; Socio-Artificial Technology; Health

Abbreviations: TS: Social Technology; AI: Artificial Intelligence; TSA: Socio Artificial Technology; PI: Intellectual Property.

\section{Contextualizing Social Technology (TS) and Artificial Intelligence (AI)}

In general, Social Technology (TS) is defined as any product, method, process or technique, created to solve some type of social problem and that meets the requirements of simplicity, low cost, easy applicability (and applicability) and impact proven social [1].

This Social Technology (TS) leads us to an innovative development proposal (economic or social), whose basis is the dissemination of solutions to essential problems in the socio-economic spheres. It is worth mentioning that these ST can originate at the community or academic level [2], linking popular knowledge to technical-scientific knowledge. In the debate about ST [3], the concern with the periphery and the most vulnerable social classes, socially, which seeks its own strategies for the solution of its problems is the fundamental point to pursue with regard to Artificial Intelligence (AI) [4], its origin is attributed to the 1950s, a time when there was a proliferation of reflections and understandings about Artificial Intelligence [5], resulting from the unfolding of the productions and discourses of the researchers Hebert Simon, Allen Newell and John Mc Carthy. For these precursors the synthetic definition of AI is: machines that learn [6].

That said, and broadening the definition of $\mathrm{AI}$ a little further, we have two general explanations. The first linked to the faculty of knowing, understanding and learning [7]. The second, more comprehensively [8], represents the ability to understand and solve new problems and conflicts and to adapt to new situations [9]. The definition of artificial intelligence involves the artifact/artifact and intelligence 
implies thinking that articulates with the representations of knowledge in the man/machine relationship [10-13].

\section{For a Socio Artificial Technology (TSA)... Perspectives}

It is based on the man / machine relationship and its interaction with the resolution of problems in the health area that we will guide an Artificial Partner Technology (TSA), involving its definition and implications. What we define as Socio Artificial Technology (TSA) is Artificial Intelligence based on Social Technology (TS) with low cost [14], coming from the solidary community based on simple algorithm, and easy to apply another piece of evidence is linked to the methodological processes presented in the texts, which are mostly positivist and given the assumption of artificial intelligence, it permeates different areas of knowledge, such as psychology, education, health, law, administration, mathematics, economics, construction, accounting and computational science [15].

Regarding the health area, it is necessary that the curricular matrices of the medical and nursing courses bring components aimed at the discussion of Social technology (TS) and Artificial Intelligence (AI) [13]. The incorporation of these disciplines in the new curricula will bring a gain in quality and qualification for the professionals who will make use of the Socio Artificial Technologies (TSA) [16], generating new processes.

Finally, it is worth mentioning the fact that these reflections are the result of postdoctoral research, under development, in the Postgraduate Program in Law at the Federal University of Bahia/Brazil in the line of research Intellectual Property (PI) and new technologies under the orientation of professor Marta Carolina Giménez Pereira [17].

\section{References}

1. Newell ASM, Simon HAP (1961) GPS, a program that simulates human thought.

2. Feigenbaum EA, Feldman J (1995) Computers and thought.

3. De Almeida P (2000) Criticisms of the theory of human capital (a contribution to the analysis of public policies in education) public education magazine 9(15): 53-70.

4. Becker GS (1994) Human capital: a theoretical and empirical analysis with special reference to education. $3^{\text {rd }}$ (Edn.), the university of Chicago press.

5. Max C (2018) Artificial intelligence: A European Perspective.

6. Goncalves CD (2008) The qualification and salary of the worker in the furniture segment of the municipality of arapongas, in Paraná. Curitiba, Dissertation (master's degree). Federal University of Paraná.

7. Richard C (1994) In the era of human capital. São Paulo: Atlas.

8. Howard G (1993) Frames of the mind: the theory of multiple intelligences, pp: 496.

9. Lucas Ruthes G (2019) Dissertation (Master). Federal University of Paraná, sector of legal sciences, postgraduate program in Law. Curitiba.

10. Kai-Fu L (2019) Artificial intelligence: how robots are changing the world, the way we love, relate, work and live. $1^{\text {st }}$ (Edn.), globe books.

11. John M, Marvin M, Nathan R, Claude S (1955) A proposal for the Dartmouth summer research project on artificial intelligence AI Magazine 27(4): 12.

12. John M, Hayes Patrick J (1969) Some philosophical problems from the standpoint of artificial intelligence. Machine intelligence, Stanford University 4: 463-502.

13. Paul ST (1988) Education investments and returns. Handbook of development Economics 1: 544-630.

14. Turing AM (1950) Computing Machinery and Intelligence.

15. (2004) United Nations Conference on Trade and Development (UNCTD).

16. Paulo S (2008) Creative Economy Report. UNCTAD, pp: 357.

17. Léon W (1983) Compendium of elements of political economy. 